\title{
How Schools Enhance the Development of Young People's Resilience
}

Michael Ungar ${ }^{1, *}$, Gerry Connelly ${ }^{2}$, Linda Liebenberg ${ }^{3}$ and Linda Theron ${ }^{4}$

\footnotetext{
${ }^{1}$ Canada Research Chair in Child, Family and Community Resilience, Dalhousie University, Halifax, Canada

2. Policy and Knowledge Mobilization, The Learning Partnership, Toronto, Canada

3.Dalhousie University, Halifax, Canada

${ }^{4}$ Department of Educational Psychology, University of Pretoria, Pretoria, South Africa
}

${ }^{*}$ Correspondence to:

Michael Ungar

michael.ungar@dal.ca

\begin{abstract}
Using a social ecological understanding of resilience, this position paper explores how schools in different contexts and across cultures influence student resilience by providing them with seven resources that are associated with better developmental outcomes for children: (1) access to material resources; (2) access to supportive relationships; (3) development of a desirable personal identity; (4) experiences of power and control; (5) adherence to cultural traditions; (6) experiences of social justice; and (7) experiences of social cohesion with others. Drawing on results from studies around the world that have assessed these seven factors, this paper makes the case that educational institutions, in collaboration with families and communities, are a form of psychosocial intervention that can improve children's resilience. Positive outcomes are most likely when there are opportunities for children to experience support for multiple coping strategies that respond to the challenges they find in different environments at school and in their communities. Our review of the research suggests that schools may have the greatest impact on resilience among children who are the most disadvantaged.
\end{abstract}

\section{Keywords}

Resilience Adolescence Social ecologies Schools Resources 


\section{A Social Ecological View of Resilience}

Resilience is generally understood as the capacity of an individual, family, community or environmental system to return to normative functioning after exposure to an atypical stressor (Ungar 2011; Allan and Ungar 2014). In the context of schools, resilience is observed when a student continues to engage and academically succeed even after he or she experiences a risk factor such as bullying or an episode of mental illness (Lal et al. 2014). This understanding of resilience, which is centered on the individual or system that recovers from stress, has in recent years shifted to a more dynamic understanding of resilience as the quality of the interactions between systems and the resources they need to do well. The bullied child is not herself resilient. Instead her resilience is a quality of herself, her school, and even the social policy and legal environment that provide resources to the child to overcome the bullying. Distinct from qualities of individuals like temperament or intelligence, resilience is best understood as patterns of interaction that occur as individuals interact with their environments to access the experiences and resources necessary to cope well under stress.

This advance to the theory of resilience means that resilience is increasingly viewed ecologically (Masten 2014; Ungar 2011). Specifically, mesosystemic interactions between a child and the child's family, school, and other service providers, make it more or less likely a child will have the necessary supports required to cope successfully with problems like depression or family violence (Kassis et al. 2013). As studies on resilience have shown, a child's positive development under stress is more often the result of a facilitative environment than the child's individual motivation or personal talents (Panter-Brick and Eggerman 2012). Approaching resilience from the perspective of a child's complex social interactions and the structures and services that facilitate the child's positive development, Ungar (2008) defines resilience as follows:

In the context of exposure to significant adversity, resilience is both the capacity of individuals to navigate their way to the psychological, social, cultural, and physical resources that sustain their well-being, and their capacity individually and collectively to negotiate for these resources to be provided in culturally meaningful ways (p. 225).

When viewed ecologically, resilience has been shown to result from a set of interactions that help children navigate towards, and negotiate access to, seven broad categories of resources: (1) material resources; (2) supportive relationships; (3) a desirable personal identity; (4) experiences of power and control; (5) adherence to cultural traditions; (6) experiences of social justice; and (7) experiences of social cohesion with others (Ungar et al. 2007). Viewed from the perspective of educational institutions, there is evidence that these seven resources can be affected by a child's experience at school in ways that make it more likely that the child will experience resilience. For example, Kumpulainen et al. (2016) contrasted how an urban Finnish and rural South African school supported the resilience of first graders. Both schools facilitated social ecological resources one through five. They did so in ways that aligned with the distinctive sociocultural context of their students. In South Africa this meant that the school tapped into the supportive relationships of its students' intergenerational and extended family systems and capitalised on the community's culture of interdependence to enable access to material resources. In contrast, the Finnish school 
prioritised peer relationships and nuclear family connections and promoted children's individual agency. The study was, however, unable to account for why the schools did not facilitate access to resources six and seven (social justice and social cohesion).

With the exception of the above study by Kumpulainen et al. (2016) and two others (TatlowGolden et al. 2015; Theron and Theron 2014), there has been inadequate attention paid to how schools facilitate access to social ecological resources in ways that make it more likely that children will experience resilience. Although there is an abundance of literature that describes school contributions to resilience (e.g., Doll 2013; Masten 2014; Theron 2016), this literature does not explicitly account for the mechanisms by which schools facilitate access to these seven resources. Thus, our purpose here is to use a social ecological model of resilience (Ungar 2008) to make the case that schools shape how these seven resources foster resilience and support student success (school engagement and academic achievement) when children's well-being is at risk.

\section{How Schools Can Use Social Ecological Resources to Enhance the Development of Resilience}

Since the 1970s, research into what supports youth resilience when young people experience significant adversity has helped to explain how to prevent youth from engaging in antisocial and criminal activities (Farrington 2000; Zubrick and Robson 2003), becoming depressed and suicidal (Forman and Kalafat 1998; Sutton 2007), and in a few instances, avoiding early school leaving (Catterall 1998; Cobb et al. 2006) and academic failure (Finn and Rock 1997; Luthar and Ansary 2005). In both low- and high-income countries, much of this preventative work takes place in schools (Fazel et al. 2014a, b). Schools have long been the site for resilience-oriented programming largely because of the easy access they provide to youth and the link between academic success, school engagement and other child development goals like self-esteem and self-efficacy (Catalano et al. 1999, 2004; Greenberg et al. 2003; Hart and Heaver 2012; Lynch et al. 2004; Ungar et al. 2014;). In addition to such formal programming, school-facilitated access to the seven social ecological resources discussed earlier has the potential to enable and/or sustain more informal pathways of resilience (Theron 2016). Increasingly, educators, school managers and school-affiliated service providers are expressing concern about the sustainability of programmatic pathways to resilience (Weare and Nind 2011) and instead promoting more support for informal systems of care.

\section{Seven Social Ecological Factors that Predict Resilience at School}

Factor 1: Access to material resources Access to material resources means a youth's access to "financial assistance, education, food, shelter and clothing, medical care, and employment" (Ungar et al. 2008, p. 7). Studies have shown that youth who have basic necessities typically demonstrate more resilience than those who have limited access to these resources (see Beauvais and Oetting 1999; Nettles et al. 2000). In an educational context, Ager et al. (2011) showed that youth who participate in educational programming in a post-conflict society like Northern Uganda tend to do better than those who are unable 
to secure educational services. Similarly, access to pre-school educational services in low SES communities in Ireland has been shown to enable young children's resilience because it provides opportunities to be fed and to play with toys that were not readily available at home (Tatlow-Golden et al. 2015). Access to these resources are believed to increase school readiness and achievement.

However, Ungar et al. (2007) argue that access alone is not enough to make children resilient. Access to material resources is transactional: "How these [resources] are provided and the degree to which each is expected varies by context as does perception of what is and is not a reasonably well-met need" (p. 6, emphasis in the original).

Factor 2: Meaningful relationships Supportive, meaningful relationships with friends, family, teachers, and community members provide a complex assortment of support for children during times of stress. Forming and maintaining trusting relationships with other people has been a consistent theme in the resilience literature (see Kumpfer 1999; Walsh 2006). As Ungar et al. (2008) explain, forming trusting relationships with others offers youth who have experienced or are currently experiencing trauma a sense of belonging, emotional support, and feelings of love, compassion, and trust. Morrison and Allen (2007) and Sharkey et al. (2008) have shown that American youth who have a positive and supportive relationship with their teachers are more likely to be engaged at school, have a sense of purpose in their lives, demonstrate higher levels of autonomy, receive higher marks, are more socially competent, and demonstrate better problem-solving skills than youth who do not. Likewise, South African street children reported that their resilience was enabled by supportive teachers who not only welcomed them into their classrooms but also encouraged peers to be unconditionally accepting (Malindi and Machenjedze 2012). In contrast, Pottinger and Stair (2009) showed that Jamaican youth who had been bullied or verbally humiliated by their teachers had increased rates of oppositional behaviours and depression, and exhibited lower levels of trust that negatively affect their resilience and school performance. Similarly, Geiger (2017) reported that 6 th grade Israeli children who experienced verbal abuse from a teacher were negatively affected, but more likely to respond with covert opposition (e.g., withdrawal from classroom activities) given the authority that Israeli teachers wield over children.

With regard to middle school students specifically, a study of over 8000 American students from schools where students were predominantly from marginalized populations or known to be performing below the norms set by other schools, showed that a supportive adult could influence positively a child's level of school engagement and achievement, even when controlling for differences in social class and race (Woolley and Bowen 2007). The study's authors concluded that when young people face multiple risk factors, "social capital assets mediate the negative influence of contextual risks on school engagement" (p. 98).

Factor 3: A desirable personal identity Development of a desirable personal identity and the self-esteem that accompanies it focuses attention on how youth think of themselves and their personal beliefs, future goals, values and strengths. Identity and self-esteem issues have been shown to be important in numerous studies of resilience (see Costigan et al. 2009; Evans et al. 2012; Settles et al. 2010). In educational contexts, Greene et al. (2004) in the United States and Shek and Ma (2012) in Hong Kong have shown that youth who 
perceive school as a means to reach their future goals and who perceive a sense of mastery over their school-based activities tend to be more engaged in and perform better at school than youth who do not. This was equally true for South African and Finnish first graders (Kumpulainen et al. 2016), as well as Maltese primary school children (Cefai 2007). Findings from Meece and Kurtz-Costes (2001) and Phalet et al. (2004) add to these findings, showing that youth who have a low sense of mastery over school work and do not see themselves as successful students, or do not perceive school as a means to reach their future goals are more likely to fail and drop out.

Factor 4: Experiences of power and control Experiences of power and control refer to children's sense of personal and collective agency, specifically, whether children believe they can control and change their lives. Research on resilience has shown that youth with greater belief in personal control (internality) tend to demonstrate resilient behaviour more often than youth who have a low sense of control (Kidd and Davidson 2007). Among abused and homeless youth, possessing a strong sense of control has been shown to be associated with social competence, better school performance, and the capacity to cope well with medical, psychological, behavioural, and emotional disorders (Cauce et al. 2003; Lin et al. 2004). Similarly, Sanders and Munford (2016) reported that responsive school-based professionals and teachers enabled a sense of control for vulnerable New Zealand youth (many of whom eventually dropped out of school because of family circumstances and/or events beyond their control) when they supported young people in ways that moderated risks (e.g., providing a place to stay or enabling time-out). South African young people from structurally disadvantaged contexts commented that teachers who encouraged them to be future-orientated, promoted a sense of control (albeit a prospective sense of control) that was integral to their resilience (Theron et al. 2013).

Factor 5: Cultural adherence Adherence to cultural traditions refers to the involvement young people experience when attached to a traditional culture, a popular culture, or, in the case of immigrants, when they occupy a third cultural space where they navigate between more than one set of cultural expectations (how the child dresses, whether the child goes out on dates, pressures on the child to perform well at school, etc.). Previous studies have shown that youth, typically racialized youth, who adopt positive cultural identities do better in school (Byrd and Chavous 2009), refrain from engaging in illegal or high-risk behaviours (Caldwell et al. 2004), and demonstrate better coping skills than youth who do not possess strong connections to their culture (Evans et al. 2012; Settles et al. 2010).

Therefore, when schools respect young people's cultural and/or ethnic identities, young people are more likely to report resilience. For example, a study that compared the resilience processes of Canadian, New Zealand and South African adolescents (Liebenberg et al. 2016) reported that when young people experienced school staff as respectful of their culture, ethnicity and spirituality, young people were more likely to report awareness of resilience-enabling resources, such as peer or educational supports. Similarly, a school climate that celebrates student diversity (including the cultural diversity of immigrant students) has been associated with resilience among youth in Greece (Motti-Stefanidi and Masten 2013). 
Factor 6: Social justice Experiences of social justice are concerned with how youth interpret forms of prejudice, discrimination, and empowerment. Studies concerning racial and ethnic discrimination conducted by Caldwell et al. (2004), Lee (2005), and Sellers et al. (2006) have shown that youth who possess strong racial and ethnic identities are better able to cope when they experience racism. Possessing a strong racial or ethnic identity is associated with youth being more aware of their rights, personal strengths, and capacity to resist racism. For ethno-racial minorities, these skills are associated with better grades (Lee 2005), less violence at school (Caldwell et al. 2004) and higher scores on measures of psychological well-being (Sellers et al. 2006). A unique study by Tinsley and Spencer (2010) showed that young people's educational expectations (how far they expect to go in school, a factor related to school engagement) can be accounted for by both teachers' expectations of a student's potential for success, and the student's belief in the availability of fair opportunities for all children in his or her country to succeed. This pattern holds for both younger and older students.

Worryingly, there are accounts of teachers and other school staff behaving in ways that lead to young people experiencing social injustice. For example, South African young people have reported experiences of teachers abusing them physically and sexually (Ngidi and Moletsane 2015) and teachers belittling them because of HIV-related challenges (Pillay and Nesengani 2006). South African young people associate such injustices at school with heightened vulnerability (Theron and Theron 2014).

Factor 7: Social cohesion The seventh and final factor identified by Ungar et al. (2007) is an experience of social cohesion. Social cohesion is described as children's experiences of spirituality, or feeling that their lives have meaning in other ways, including that their presence matters and is noticed. A sense of belonging at school synonymous with school engagement creates among children a concurrent sense of cohesion outside of school in their communities. Fredricks et al. (2004) define school engagement as youth's behaviour in school, their emotional attachment to school, the level of importance they place on receiving an education, and their academic achievement. In contexts where school performance is important to the child's family, or attendance at school prevents exposure to risk factors present elsewhere in a child's life, higher levels of school engagement have been shown to protect youth from peer, family and community risk factors (Fred ricks et al. 2004). For example, Phasha (2010) reported that commitment to schooling and subsequent tertiary education was integral to the resilience of black South African girls who had been sexually assaulted. This commitment aligns with African valuing of education and concomitant opportunities for improved life circumstances (Theron and Phasha 2015). For marginalized youth, school engagement may provide one of the few spaces in their lives where they experience connections that contribute to positive developmental outcomes like a sense of self-worth, attachment to adults and self-efficacy (Dotterer et al. 2009). In contrast, studies conducted by Ripski and Gregory (2009), O’Brennan and Furlong (2010), and Toomey and Russell (2013) have shown that American schools with environments that students perceive as unsafe and hostile, and that provide little support to children who experience adversity, are likely to report lower levels of student engagement and lower overall academic performance. 


\section{Interrelated Factors}

The descriptions of these seven factors associated with resilience show that they are interrelated, with achievement in one area likely to influence a child's success in another. This pattern of interaction can be found in a number of studies. For example, a 2009 report by the McCreary Centre Society, a not-for-profit research group that specializes in improving the health of youth in Canada, showed that among 29,000 public school children in grades 7-12 (Smith et al. 2009), those who built and maintained meaningful relationships with their school and family despite their level of risk, and who showed adherence to their heritage culture, had a greater capacity to navigate their way through negative life experiences and choose prosocial solutions to problems. Students who reported high levels of connectedness to school also reported significantly lower rates of binge drinking, suicide attempts, and poor physical health compared to youth with low scores on school engagement. Beyond the school, youth who reported positive relationships with family and friends reported lower levels of alcohol use, cigarette use, and fighting than students who did not have positive relationships with family and friends. Finally, youth who reported high levels of connectedness to their culture and ethnicity reported lower rates of binge drinking, fighting and carrying a weapon, poor health, and suicidal thoughts than youth who reported low levels of cultural and/or ethnic connection.

Facilitating youth resilience, however, has been shown to require more than just school attendance (Hines et al. 2005). Rather, resilience is influenced by young people's access to multiple social ecological resources while at school (beyond classroom instruction in academic subjects) and in their communities. These usually include in some form meaningful relationships with friends, family members, teachers, and other school staff (Klem and Connell 2004; Shin et al. 2007; Murray 2009). For example, South African young people who beat the challenges of structural disadvantage and who navigated their way to university, reported high levels of personal agency that were prompted and sustained not only by extended family but also by their educators (Theron and Theron 2014). In their retrospective accounts of their resilience, young people credited teachers in particular with facilitating access to food, clothing and education; providing relational support; nurturing positive self-belief and a powerful personal identity; and supporting experiences of social justice. All these experiences are not typically part of a teacher's job description or an academic curriculum.

Likewise, schools that provide students with meaningful roles within their schools, instil a sense of leadership and provide opportunities to impact school policies have been shown to increase engagement among those vulnerable to school dropout (Lizzio et al. 2011; Whitlock 2006). Schools also contribute to other constellations of factors associated with resilience when they help children access free or subsidized lunch programs or implement a culturally relevant curriculum (Hinrichs 2010; Kana'iaupuni et al. 2011). Furthermore, the school environment plays a role in facilitating resilience when it prevents bullying and discrimination that can contribute to students disengagement from school ( $O^{\prime} B r e n n a n$ and Furlong 2010; Ripski and Gregory 2009; Toomey and Russell 2013). Finally, establishing support groups for youth who face discrimination has been shown to increase a sense of belonging to school and improve academic performance (Toomey and Russell 2013). 


\section{How Schools Can Build Resilience}

As this position paper argues, by enabling the seven social ecological resources (Ungar et al. 2007) schools can facilitate students' access to individual, relational and contextual resources that are associated with better academic engagement, performance and overall mental and physical well-being. However, while there are many ways that schools can either actively or passively promote resilience, greater complexity is required in how we conceptualize the factors that make children resilient and the interactions between individual, school, family and community factors. As has been shown, protective processes like school engagement are influenced by cultural, family, and community factors that schools themselves may not be able to influence alone. A multisystemic, coordinated approach to building resilience may be more effective than a program that is just school specific (Bierman et al. 2008; Webster-Stratton et al. 2008).

The evidence that has been presented also suggests that efforts by educators to promote resilience should be tailored to the unique risks that a subpopulation of youth experience (Ungar et al. 2014). Spence and Shortt (2007) have argued that universal programs are ineffectual because they assume that every child faces the same risks despite differences in gender, race, class, and other characteristics. Uniform administration of an intervention, or the assumption that a single protective factor is relevant to all youth, can overlook the specific needs of youth who are affected by contextually specific problems. For example, Chavous et al. (2008) have shown this in their study of race-based education programs where issues of gender were neglected. As a consequence, female students received unequal services when compared to male students. Similar criticisms have been made by other researchers such as Bottrell (2007) who argued that programs are often designed from the point of view of educators and, therefore, it is educators, rather than young people themselves, who define what appropriate, successful, and resilient behaviours are as well as how problems should be solved.

With this complexity in mind, it is possible to interpret the research as indicating the need to enhance all seven resilience-promoting resources simultaneously. In general, the more of these seven resources that are made available and accessible, the more likely young people are to succeed at school and in their communities. School's that are designed not only to provide educational opportunities, but also see themselves as a source of support for overall student resilience are those which will be effective at stimulating student engagement, academic achievement and the well-being of young people across many different domains of their lives.

\section{Recommendations for Future Research}

More research is needed to explore the relative amount of influence that different individual and ecological factors exert on both school performance and overall child wellbeing, as well as the role schools can play in promoting children's access to protective factors that increase resilience. Emerging research in this area suggests the need to account for the differential impact of resilience-promoting factors on young people at low and high 
levels of risk exposure, with the greatest impact of these resources on the most marginalized children and youth (Ungar in press). With regard to research, this means that the next wave of resilience research in schools should investigate whether all children benefit equally from the same programming or if some programming has a greater impact on children who have the most challenges. Studies that investigate this differential impact are likely to challenge the notion of universal access to educational resources and instead promote more individualized programming for children with greater needs.

A contextualized understanding of how schools can influence the resilience of their students supposes that resilience is the result of interactions between individuals and their social ecologies, with the environment exerting a disproportionately large influence on children who are most at risk (Jaffee et al. 2007; Ungar 2011, 2016). Therefore, future research with schools needs to also gather data on both individual and ecological factors in the same study. We need to ask, "Which factors nurture and sustain resilience, for which children, in which contexts, when they are exposed to what threats to their psychosocial development?" For this reason, there is a need to continue to develop models of intervention and conduct research that helps us understand the complex, multi-tiered way the factors associated with resilience interact.

\section{Conclusion}

Students face a wide array of barriers in their lives that not only jeopardize their performance in school and school completion but also jeopardize their safety and psychological well-being in ways that can follow them into their adult lives. There is emerging evidence that schools have the potential to positively influence children's biopsychosocial growth and development though much more work needs to be done to identify which protective factors are most likely to be strengthened at school, the role schools can play in collaborations with children's families and communities, and to what extent interventions need to focus on changing individual students or changing the quality of their school, home and community environments.

\section{Acknowledgements}

Funding was provided by Social Sciences and Humanities Research Council of Canada (Grant No. 885-2008-1000).

\section{References}

Ager, A., Akesson, B., Stark, L., Flouri, E., Okot, B., McCollister, F., et al. (2011). The impact of the school-based psychosocial structured activities (PSSA) program on conflict-affected children in northern Uganda. Journal of Child Psychology and Psychiatry, 52(11), 1124-1133. doi:10.1111/j.1469-7610.2011.02407.x. 
Allan, R., \& Ungar, M. (2014). Resilience-building interventions with children, adolescents, and their families. In S. Prince-Embury \& D. H. Saklofske (Eds.), Resilience interventions for youth in diverse populations (pp. 447-462). New York: Springer.

Beauvais, F., \& Oetting, E. R. (1999). Drug use, resilience, and the myth of the golden child. In J. L. Johnson (Ed.), Resilience and development: Positive life adaptations. New York: Kluwer Academic/Plenum Press.

Bierman, K. L., Domitrovich, C. E., Nix, R. L., Gest, S. D., Welsh, J. A., Greenberg, M. T., et al. (2008). Promoting academic and social-emotional school readiness: The Head Start REDI Program. Child Development, 79(6), 1802-1817.

Bottrell, D. (2007). Resistance, resilience and social identities: Reframing "problem youth" and the problem of schooling. Journal of Youth Studies, 10(5), 597-616.

Byrd, C., \& Chavous, T. (2009). Racial identity and academic achievement in the neighborhood context: A multilevel analysis. Journal of Youth and Adolescence, 38(4), 544559.

Caldwell, C., Kohn-Wood, L., Schmeelk-Cone, K., Chavous, T., \& Zimmerman, M. (2004). Racial discrimination and racial identity as risk or protective factors for violent behaviors in African American young adults. American Journal of Community Psychology, 33(1/2), 91105.

Catalano, R., Berglund, M., Ryan, J., Lonczak, H., \& Hawkins, J. (1999). Positive youth development in the United States: Research findings on evaluations of positive youth development programs. Seattle, WA: U.S. Department of Health and Human Services, Office of the Assistant Secretary for Planning and Evaluation, National Institute for Child Health and Human Development.

Catalano, R. F., Berglund, M. L., Ryan, J., Lonczak, H. S., \& Hawkins, J. D. (2004). Positive youth development in the United States: Research findings on evaluations of Positive Youth Development programs. The ANNALS of the American Academy of Political and Social Science, 591(1), 98-124.

Catterall, J. S. (1998). Risk and resilience in student transitions to high school. American Journal of Education, 106(2), 302-333.

Cauce, A. M., Stewart, A., Rodriguez, M., Cochran, B., \& Ginzler, J. (2003). Overcoming the odds? Adolescent development in the context of urban poverty. In S. S. Luthar (Ed.), Resilience and vulnerability: Adaptation in the context of childhood adversities (pp. 343363). New York: Cambridge University Press.

Cefai, C. (2007). Resilience for all: A study of classrooms as protective contexts. Emotional \& Behavioural Difficulties, 12(2), 119-134. doi:10.1080/13632750701315516.

Chavous, T., Rivas-Drake, D., Smalls, C., Griffin, T., \& Cogburn, C. (2008). Gender matters, too: The influences of school racial discrimination and racial identity on academic 
engagement outcomes among African American adolescents. Developmental Psychology, $44(3), 637-654$.

Cobb, B., Sample, P. L., Alwell, M., \& Johns, N. R. (2006). Cognitive-behavioral interventions, dropout, and youth with disabilities: A systematic review. Remedial and Special Education, $27(5), 259-275$.

Costigan, C., Su, T. F., \& Hua, J. M. (2009). Ethnic identity among Chinese Canadian youth: A review of the Canadian literature. Canadian Psychology, 50(4), 261-272.

Doll, B. (2013). Enhancing resilience in classrooms. In S. Goldstein \& R. B. Brooks (Eds.), Handbook of resilience in children (2nd ed., pp. 399-409). New York, NY: Springer.

Dotterer, A. M., McHale, S. M., \& Crouter, A. C. (2009). Sociocultural factors and school engagement among African American youth: The roles of racial discrimination, racial socialization, and ethnic identity. Applied Developmental Science, 13(2), 61-73.

Evans, A. B., Banerjee, M., Meyer, R., Aldana, A., Foust, M., \& Rowley, S. (2012). Racial socialization as a mechanism for positive development among African American youth. Child Development Perspectives, 6(3), 251-257.

Farrington, D. P. (2000). Explaining and preventing crime: The globalization of knowledgethe American Society of Criminology 1999 Presidential Address. Criminology, 38(1), 1-24.

Fazel, M., Hoagwood, K., Stephan, S., \& Ford, T. (2014a). Mental health interventions in schools in high-income countries. The Lancet Psychiatry, 1(5), 377-387. doi:10.1016/S22150366(14)70312-8.

Fazel, M., Patel, V., Thomas, S., \& Tol, W. (2014b). Mental health interventions in schools in low-income and middle-income countries. The Lancet Psychiatry, 1(5), 388-398. doi:10.1016/S2215-0366(14)70357-8.

Finn, J. D., \& Rock, D. A. (1997). Academic success among students at risk for school failure. Journal of Applied Psychology, 82(2), 221-234.

Forman, S., \& Kalafat, J. (1998). Substance abuse and suicide: Promoting resilience against self-destructive behavior in youth. School Psychology Review, 27(3), 398-406.

Fredricks, J., Blumenfeld, P., \& Paris, A. (2004). School engagement: Potential of the concept, state of the evidence. Review of Educational Research, 74(1), 59-109.

Geiger, B. (2017). Sixth graders in Israel recount their experience of verbal abuse by teachers in the classroom. Child Abuse and Neglect, 63, 95-105.

Greenberg, M. T., Weissberg, R. P., O’Brien, M. U., Zins, J. E., Fredericks, L., Resnik, H., et al. (2003). Enhancing school-based prevention and youth development through coordinated social, emotional, and academic learning. American Psychologist, 58(6/7), 466-474. 
Greene, B., Miller, R., Crowson, H., Duke, B., \& Akey, K. (2004). Predicting high school students' cognitive engagement and achievement: Contributions of classroom perceptions and motivation. Contemporary Educational Psychology, 29(4), 462-482.

Hart, A., \& Heaver, B. (2012). School-based resilience interventions with disadvantaged young people: Towards a systematic consultative review. Today's Children Tomorrow's Parents: An Interdisciplinary Journal, 33-34, 53-64.

http://www.tctp.cicop.ro/documente/Revista\%2033-34\%20EN.pdf\#page=55

Hines, A., Merdinger, J., \& Wyatt, P. (2005). Former foster youth attending college: Resilience and the transition to young adulthood. American Journal of Orthopsychiatry, 75(3), 381-394.

Hinrichs, P. (2010). The effects of the National School Lunch Program on education and health. Journal of Policy Analysis and Management, 29(3), 479-505.

Jaffee, S. R., Caspi, A., Moffitt, T. E., Polo-Tomas, M., \& Taylor, A. (2007). Individual, family, and neighborhood factors distinguish resilient from non-resilient maltreated children: $A$ cumulative stressors model. Child Abuse and Neglect, 31, 231-253.

Kana'iaupuni, S., Ledward, B., \& Keohokalole, K. (2011). New research on the impact of cultural influences in education on Native Hawaiian student outcomes. AAPI NEXUS, 9(1\&2), 221-229.

Kassis, W., Artz, S., \& Moldenhauer, S. (2013). Laying down the family burden: A crosscultural analysis of resilience in the midst of family violence. Child \& Youth Services, 34, 3763.

Kidd, S. A., \& Davidson, L. (2007). "You have to adapt because you have no other choice": The stories of strength and resilience of 208 homeless youth in New York City and Toronto. Journal of Community Psychology, 35(2), 219-238.

Klem, A., \& Connell, J. (2004). Relationships matter: Linking teacher support to student engagement and achievement. Journal of School Health, 74(4), 262-273.

Kumpfer, K. (1999). Factors and processes contributing to resilience: The resilience framework. In J. Johnson (Ed.), Resilience and development: Positive life adaptations (pp. 179-224). New York: Plenum Press.

Kumpulainen, K., Theron, L. C., Kahl, C., Mikkola, A., Salmi, S., Bezuidenhout, C., et al. (2016). Children's positive adjustment to first grade in risk-filled communities: A case study of the role of school ecologies in South Africa and Finland. School Psychology International, 37, 121-139. doi:10.1177/0143034315614687.

Lal, S., Ungar, M., Malla, A. K., Frankish, J., \& Suto, M. J. (2014). Meanings of well-being from the perspectives of youth recently diagnosed with psychosis. Journal of Mental Health, 23(1), 25-30. 
Lee, S. (2005). Up against whiteness: Race, school, and immigrant youth. New York: Teachers College Press.

Liebenberg, L., Theron, L. C., Sanders, J., Munford, R., Van Rensburg, A., Rothmann, S., et al. (2016). Bolstering resilience through teacher-student interaction: Lessons for school psychologists. School Psychology International, 37(2), 140-154.

doi:10.1177/0143034315614689.

Lin, K., Sandler, I., Ayers, T., Wolchik, S., \& Luecken, L. (2004). Resilience in parentally bereaved children and adolescents seeking preventive services. Journal of Clinical Child \& Adolescent Psychology, 33(4), 673-683.

Lizzio, A., Dempster, N., \& Neumann, R. (2011). Pathways to formal and informal student leadership: The influence of peer and teacher-student relationships and level of school identification on students' motivations. International Journal of Leadership in Education, 14(1), 85-102.

Luthar, S. S., \& Ansary, N. S. (2005). Dimensions of adolescent rebellion: Risks for academic failure among high- and low-income youth. Development and Psychopathology, 17(1), 231250.

Lynch, K. B., Geller, S. R., \& Schmidt, M. G. (2004). Multi-year evaluation of the effectiveness of a resilience-based prevention program for young children. The Journal of Primary Prevention, 24(3), 335-353.

Malindi, M. J., \& Machenjedze, N. (2012). The role of school engagement in strengthening resilience among male street children. South African Journal of Psychology, 42(1), 71-81. doi:10.1177/008124631204200108.

Masten, A. S. (2014). Ordinary magic. Resilience in development. New York, NY: Guilford Press.

Meece, J., \& Kurtz-Costes, B. (2001). Introduction: The schooling of ethnic minority children and youth. Educational Psychologist, 36(1), 1-7.

Morrison, G., \& Allen, M. (2007). Promoting student resilience in school contexts. Theory into Practice, 46(2), 162-169.

Motti-Stefanidi, F., \& Masten, A. S. (2013). School success and school engagement of immigrant children and adolescents: A risk and resilience developmental perspective. European Psychologist, 18(2), 126-135. doi:10.1027/1016-9040/a000139.

Murray, C. (2009). Parent and teacher relationships as predictors of school engagement and functioning among low-income urban youth. Journal of Early Adolescence, 29(3), 376-404.

Nettles, S., Mucherah, W., \& Jones, D. (2000). Understanding resilience: The role of social resources. Journal of Education for Students Placed at Risk, 5(2), 47-60. 
Ngidi, N. D., \& Moletsane, R. (2015). Using transformative pedagogies for the prevention of gender-based violence: Reflections from a secondary school-based intervention. Agenda, 29(3), 66-78.

O’Brennan, L., \& Furlong, M. (2010). Relations between students' perceptions of school connectedness and peer victimization. Journal of School Violence, 9(4), 375-391.

Panter-Brick, C., \& Eggerman, M. (2012). Understanding culture, resilience, and mental health: The production of hope. In M. Ungar (Ed.), The social ecology of resilience: $A$ handbook of theory and practice (pp. 369-386). New York: Springer.

Phalet, K., Andriessen, I., \& Lens, W. (2004). How future goals enhance motivation and learning in multicultural classrooms. Educational Psychology Review, 16(1), 59-89.

Phasha, T. N. (2010). Educational resilience among African survivors of child sexual abuse in South Africa. Journal of Black Studies, 40(6), 1234-1253. doi:10.1177/0021934708327693.

Pillay, J., \& Nesengani, R. I. (2006). The educational challenges facing early adolescents who head families in rural Limpopo province. Education as Change, 10(2), 131-147.

Pottinger, A. M., \& Stair, A. G. (2009). Bullying of students by teachers and peers and its effect on the psychological well-being of students in Jamaican schools. Journal of School Violence, 8(4), 312-327.

Ripski, M., \& Gregory, A. (2009). Unfair, unsafe, and unwelcome: Do high school students' perceptions of unfairness, hostility, and victimization in school predict engagement and achievement? Journal of School Violence, 8(4), 355-375.

Sanders, J., \& Munford, R. (2016). Fostering a sense of belonging at school: Five orientations to practice that assist vulnerable youth to create a positive student identity. School Psychology International, 37(2), 155-171. doi:10.1177/0143034315614688.

Sellers, R. M., Copeland-Linder, N., Martin, P. P., \& Lewis, R. H. (2006). Racial identity matters: The relationship between racial discrimination and psychological functioning in African American adolescents. Journal of Research on Adolescence, 16(2), 187-216.

Settles, I. H., Navarrete, C. D., Pagano, S. J., Abdou, C. M., \& Sidanius, J. (2010). Racial identity and depression among African American women. Cultural Diversity and Ethnic Minority Psychology, 16(2), 248-255.

Sharkey, J., You, S., \& Schnoebelen, K. (2008). Relations among school assets, individual resilience, and student engagement for youth grouped by level of family functioning. Psychology in the Schools, 45(5), 402-418.

Shek, D., \& Ma, C. (2012). Impact of the Project P.A.T.H.S. in the junior secondary school years: Objective outcome evaluation based on eight waves of longitudinal data. The Scientific World. doi:10.1100/2012/170345. 
Shin, R., Daly, B., \& Vera, E. (2007). The relationships of peer norms, ethnic identity, and peer support to school engagement in urban youth. Professional School Counseling, 10(4), 379-388.

Smith, A., Stewart, D., Peled, M., Poon, C., Saewyc, E., \& McCreary Centre Society. (2009). A picture of health: Highlights from the 2008 BC Adolescent Health Survey. Vancouver, BC: McCreary Centre Society.

Spence, S., \& Shortt, A. (2007). Research review: Can we justify the widespread dissemination of universal, school-based interventions for the prevention of depression among children and adolescents? Journal of Child Psychology and Psychiatry, 48(6), 526542.

Sutton, J. M. (2007). Prevention of depression in youth: A qualitative review and future suggestions. Clinical Psychology Review, 27(5), 552-571.

Tatlow-Golden, M., O'Farrelly, C., Booth, A., O'Rourke, C., \& Doyle, O. (2015). 'Look, I have my ears open': Resilience and early school experiences among children in an economically deprived suburban area in Ireland. School Psychology International, 37(2), 104-120.

Theron, L., Liebenberg, L., \& Malindi, M. (2013). When schooling experiences are respectful of children's rights: A pathway to resilience. School Psychology International, 35(3), 253265. doi:10.1177/0142723713503254.

Theron, L. C. (2016). The everyday ways that school ecologies facilitate resilience: Implications for school psychologists. School Psychology International, 37, 87-103. doi:10.1177/0142723713503254.

Theron, L. C., \& Phasha, N. (2015). Cultural pathways to resilience: Opportunities and obstacles as recalled by black South African students. In L. C. Theron, L. Liebenberg, \& M. Ungar (Eds.), Youth resilience and culture: Commonalities and complexities (pp. 51-66). Dordrecht: Springer.

Theron, L. C., \& Theron, A. M. C. (2014). Education services and resilience processes: Resilient black South African students' experiences. Child and Youth Services Review, 47(3), 297-306. doi:10.1016/j.childyouth.2014.10.003.

Tinsley, B., \& Spencer, M. B. (2010). High hope and low regard: The resiliency of adolescents' educational expectations while developing in challenging political contexts. Research in Human Development, 7(3), 183-201.

Toomey, R., \& Russell, S. (2013). Gay-straight alliances, social justice involvement, and school victimization of lesbian, gay, bisexual, and queer youth: Implications for school wellbeing and plans to vote. Youth \& Society, 45(34), 500-522. doi:10.1177/0044118X11422546.

Ungar, M. (2008). Resilience across cultures. British Journal of Social Work, 38(2), 218-235. 
Ungar, M. (2011). The social ecology of resilience: Addressing contextual and cultural ambiguity of a nascent construct. American Journal of Orthopsychiatry, 81(1), 1-17.

Ungar, M. (2016). Which counts more? The differential impact of the environment or the differential susceptibility of the individual? British Journal of Social Work. doi:10.1093/bjsw/bcw109.

Ungar, M. (in press). Which counts more? The differential impact of the environment or the differential susceptibility of the individual? British Journal of Social Work.

Ungar, M., Brown, M., Liebenberg, L., Cheung, M., \& Levine, K. (2008). Distinguishing differences in pathways to resilience among Canadian youth. Canadian Journal of Community Mental Health, 27(1), 1-13.

Ungar, M., Brown, M., Liebenberg, L., Othman, R., Kwong, W. M., Armstrong, M., et al. (2007). Unique pathways to resilience across cultures. Adolescence, 42(166), 287-310.

Ungar, M., Russell, P., \& Connelly, G. (2014). School-based interventions to enhance the resilience of students. Journal of Educational and Developmental Psychology, 4(1), 66-83. doi:

Walsh, F. (2006). Strengthening family resilience. New York: Guildford Press.

Weare, K., \& Nind, M. (2011). Mental health promotion and problem prevention in schools: What does the evidence say? Health Promotion International, 26(Suppl. 1), i29-i69. doi:10.1093/heapro/dar075.

Webster-Stratton, C., Reid, M., \& Stoolmiller, M. (2008). Preventing conduct problems and improving school readiness: Evaluation of the Incredible Years Teacher and Child Training Programs in high-risk schools. Journal of Child Psychology and Psychiatry, 49(5), 471-488.

Whitlock, J. L. (2006). Youth perceptions of life at school: Contextual correlates of school connectedness in adolescence. Applied Developmental Science, 10(1), 13-29.

Woolley, M., \& Bowen, G. (2007). In the context of risk: Supportive adults and the school engagement of middle school students. Family Relations, 56(1), 92-104.

Zubrick, S., \& Robson, A. (2003). Resilience to offending in high-risk groups: Focus on Aboriginal youth. Report for the Telethon Institute for Child Health Research Australia. Canberra, Government of Australia. 